\title{
Synthesis of Branched Polyethylene with "Half- Sandwich" Pyridine-imine Nickel Complexes
}

\author{
Zhou Chen, ${ }^{1,2}$ Kate E. Allen, ${ }^{1}$ Peter S. White, ${ }^{1}$ Olafs Daugulis, ${ }^{2 *}$ and Maurice Brookhart ${ }^{1,2 *}$ \\ ${ }^{1}$ Department of Chemistry, University of North Carolina at Chapel Hill, Chapel Hill, North Carolina, 27599-3290 \\ ${ }^{2}$ Department of Chemistry, University of Houston, Houston, TX 77204-5003.
}

Table of contents

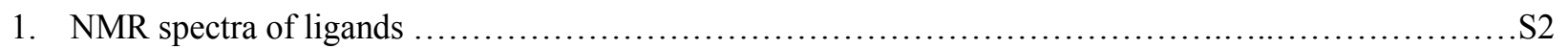

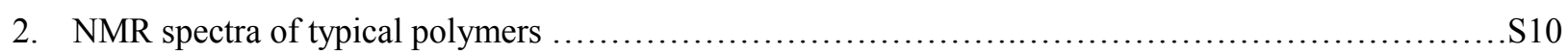



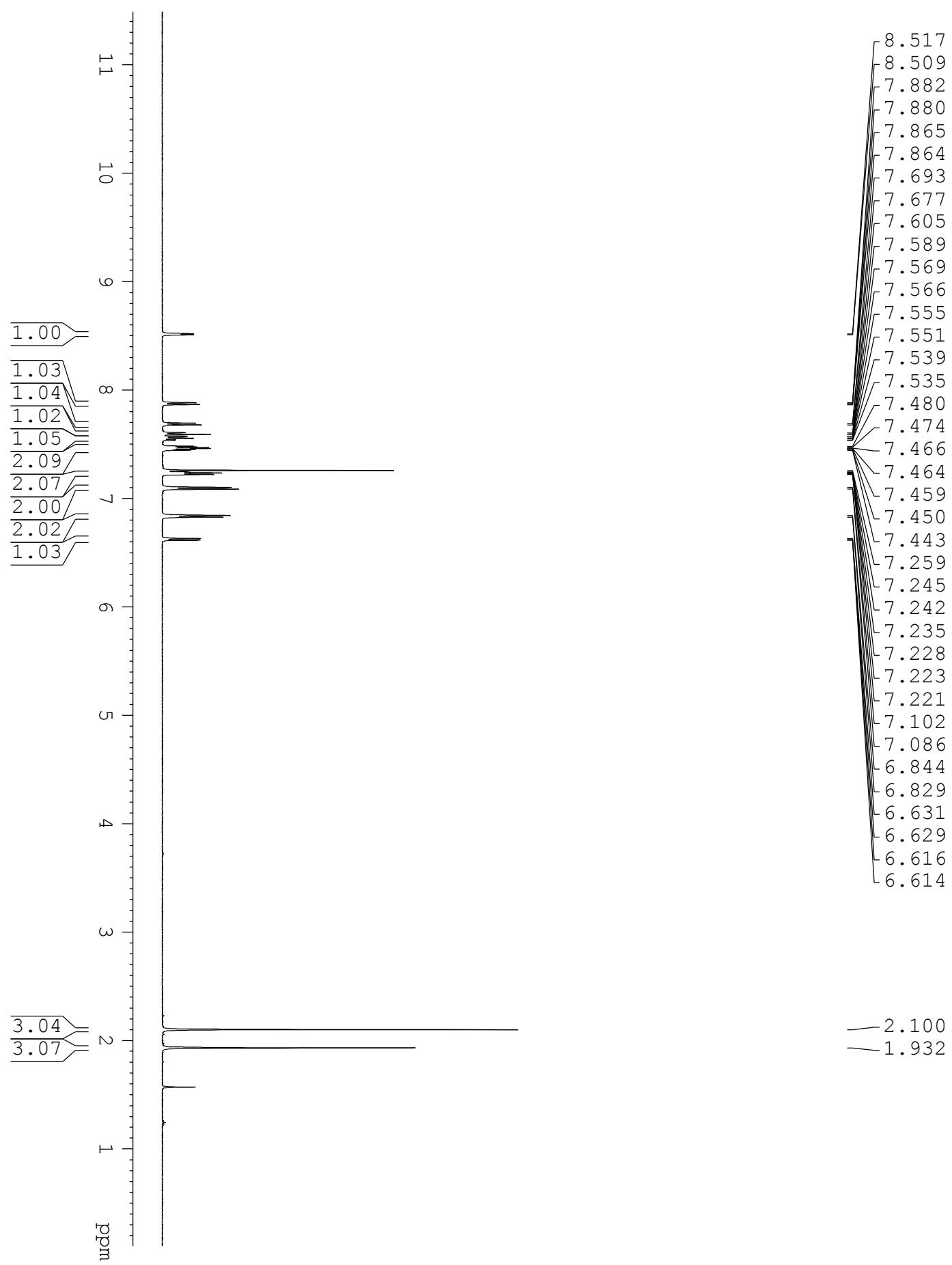

Figure S1: ${ }^{1} \mathrm{H}$ NMR of $\mathbf{L} 1\left(500 \mathrm{MHz}, \mathrm{CDCl}_{3}\right)$ 


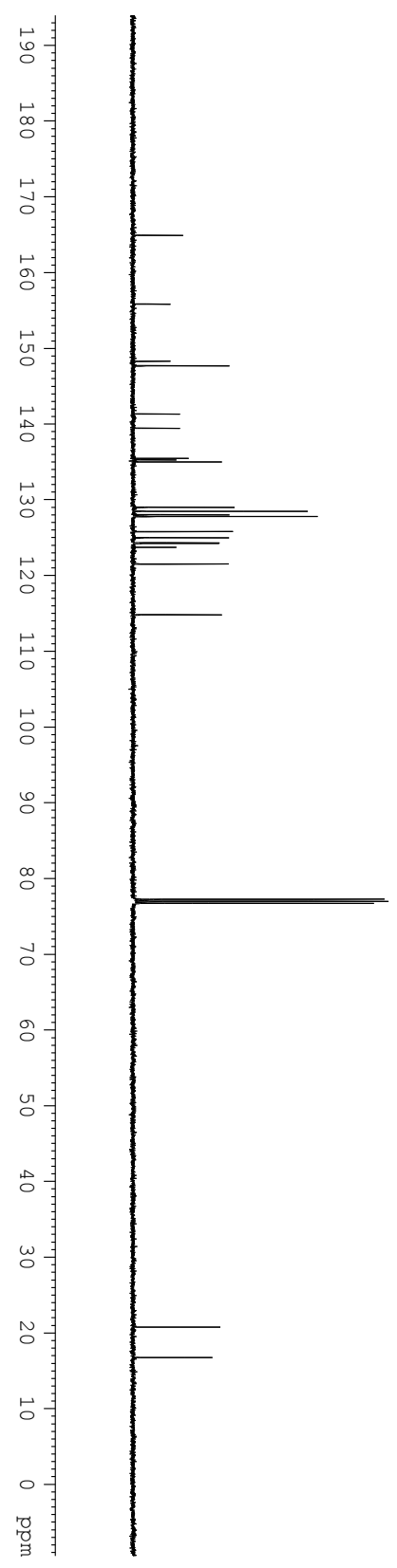

164.905

155.819

148.286

147.690

141.343

139.452

135.476

135.273

] 135.000

128.990

$-128.475$

$-128.001$

- 127.788

$-125.789$

124.987

124.321

124.248

123.730

L121.522

114.809

77.242

$-76.987$

$-76.734$

$-20.755$

$-16.750$

Figure S2: ${ }^{13} \mathrm{C}$ NMR of $\mathbf{L} \mathbf{1}\left(125 \mathrm{MHz}, \mathrm{CDCl}_{3}\right)$ 

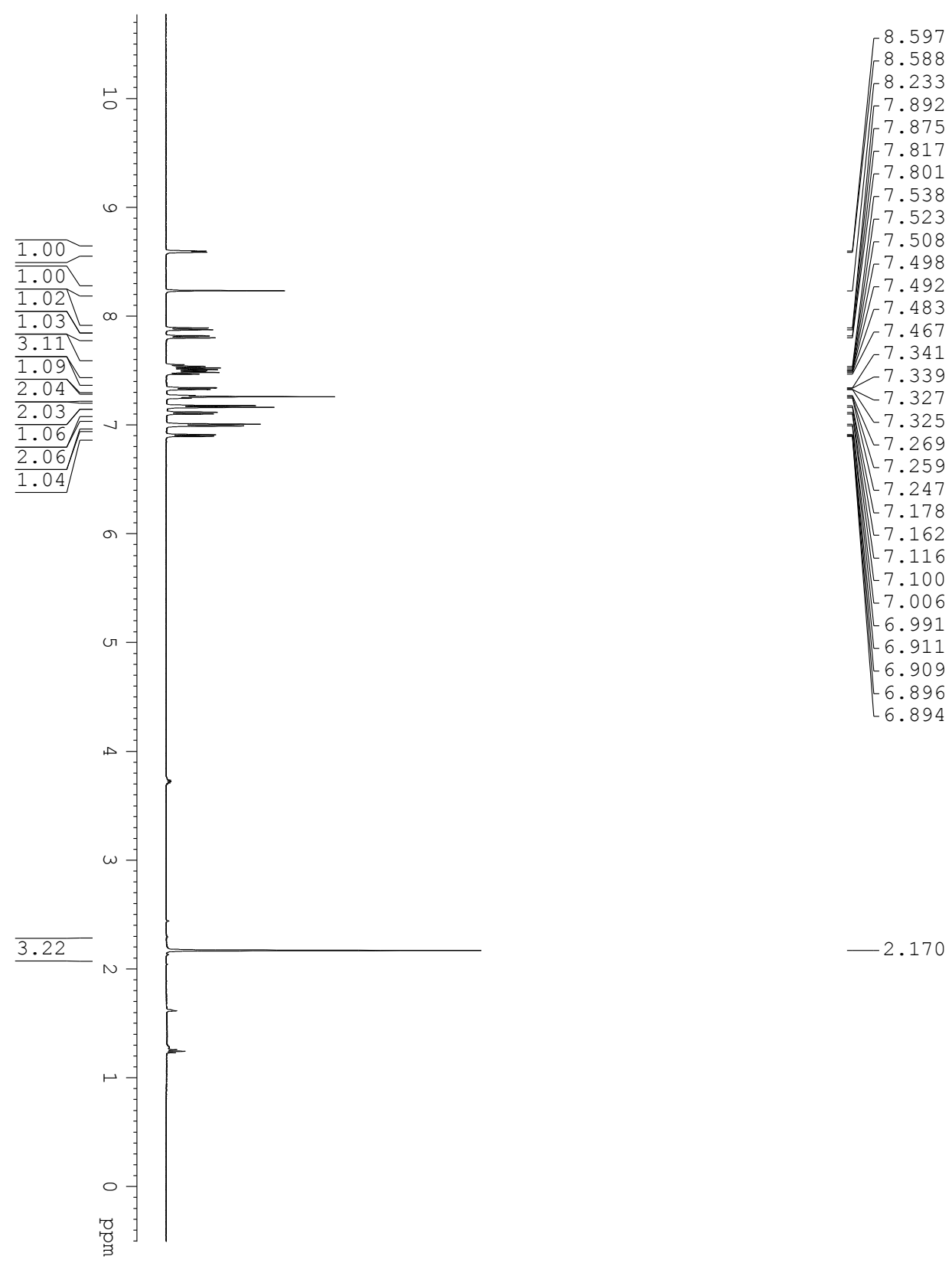

Figure S3: ${ }^{1} \mathbf{H}$ NMR of $\mathbf{L} 2\left(500 \mathrm{MHz}, \mathrm{CDCl}_{3}\right)$ 

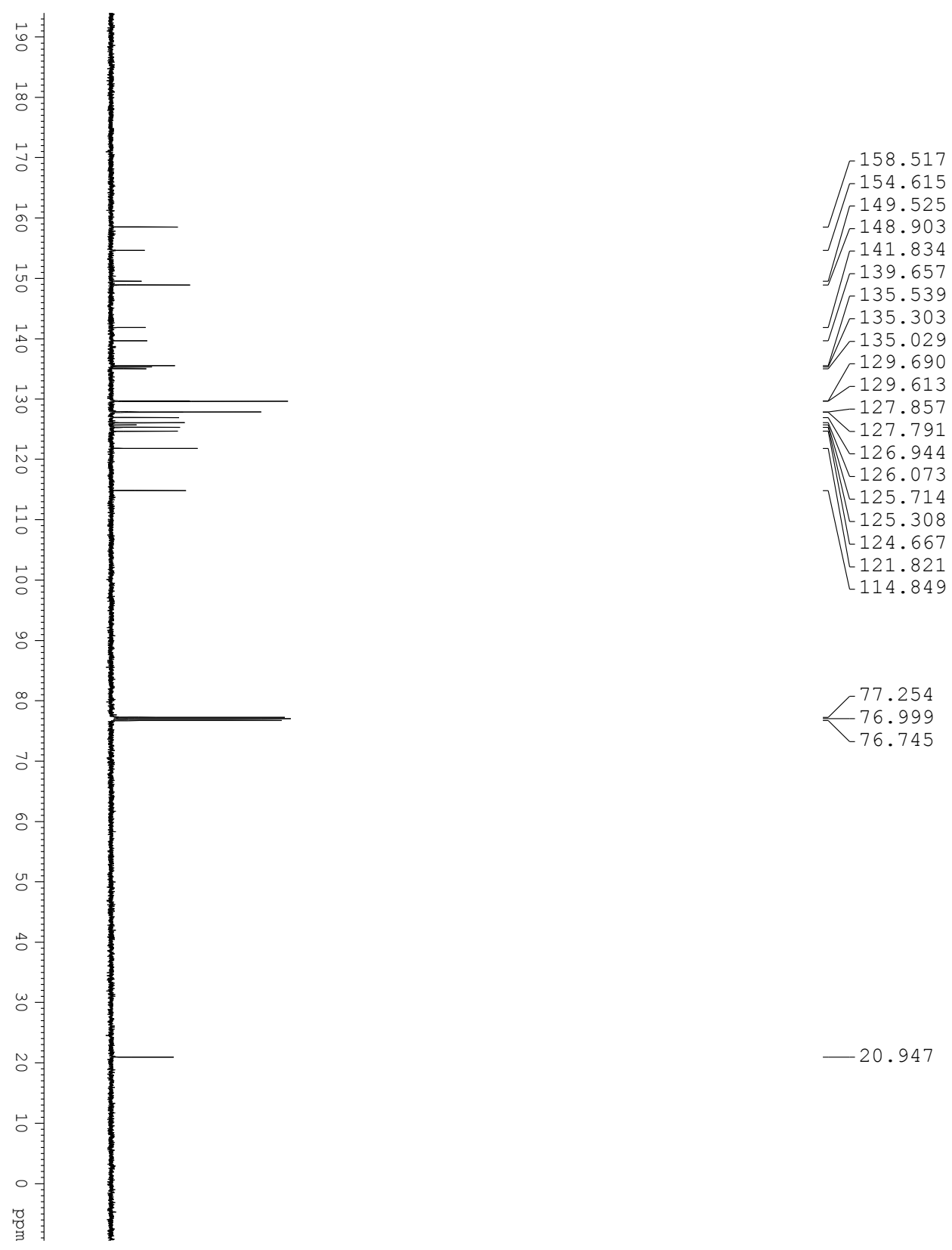

$-20.947$

Figure S4: ${ }^{13} \mathrm{C}$ NMR of $\mathbf{L} 2\left(125 \mathrm{MHz}, \mathrm{CDCl}_{3}\right)$ 

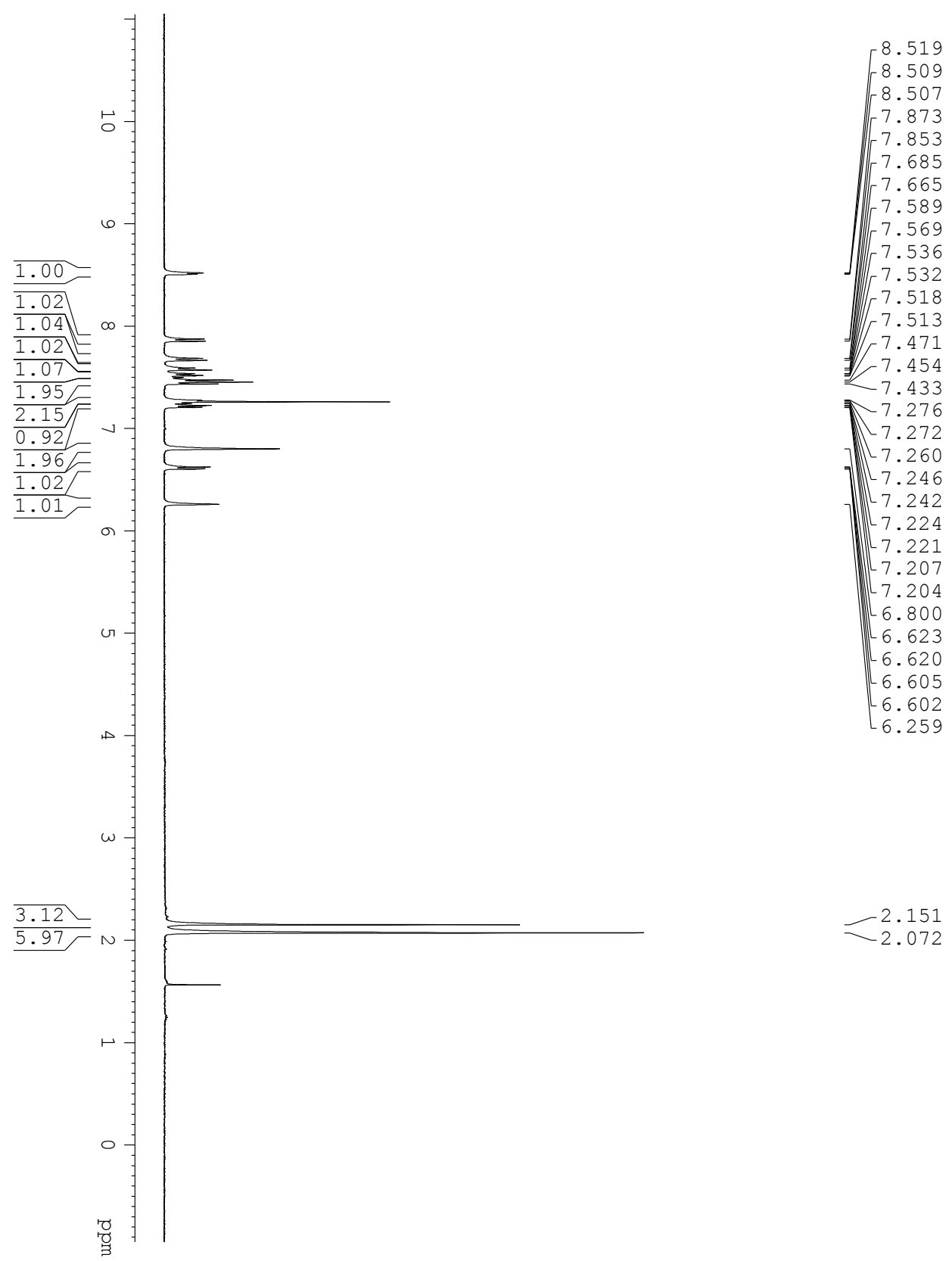

$-2.151$

$-2.072$

Figure S5: ${ }^{1} \mathrm{H}$ NMR of $\mathbf{L} 3\left(400 \mathrm{MHz}, \mathrm{CDCl}_{3}\right)$ 


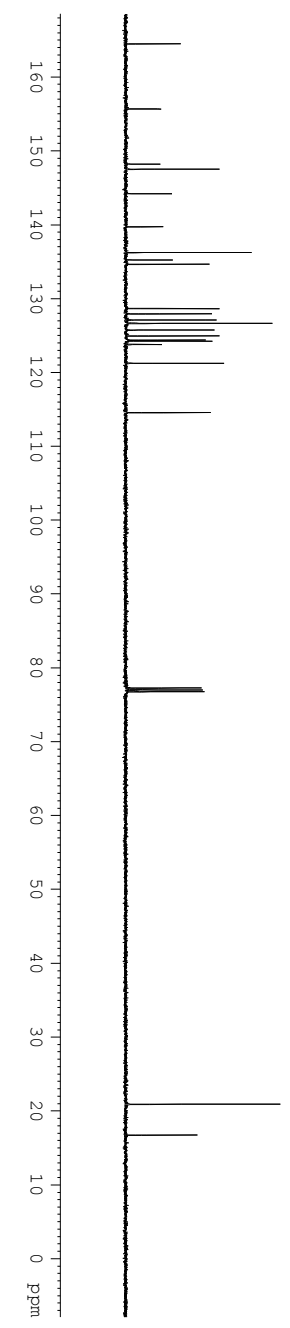

$-164.448$

155.632
148.164

$\int \begin{array}{r}148.164 \\ 147.481\end{array}$ 144.168

J 139.676

136.211

135.214

$\int[135.214$

128.616

127.902

$-127.084$

$-126.613$

ㄴ. 125.722

$-124.917$

124.365

124.22

123.750

121.213

$-114.542$

77.253

76.999
-76.744

$-20.884$

$-16.729$

Figure S6: ${ }^{13} \mathrm{C}$ NMR of $\mathbf{L 3}\left(125 \mathrm{MHz}, \mathrm{CDCl}_{3}\right)$ 


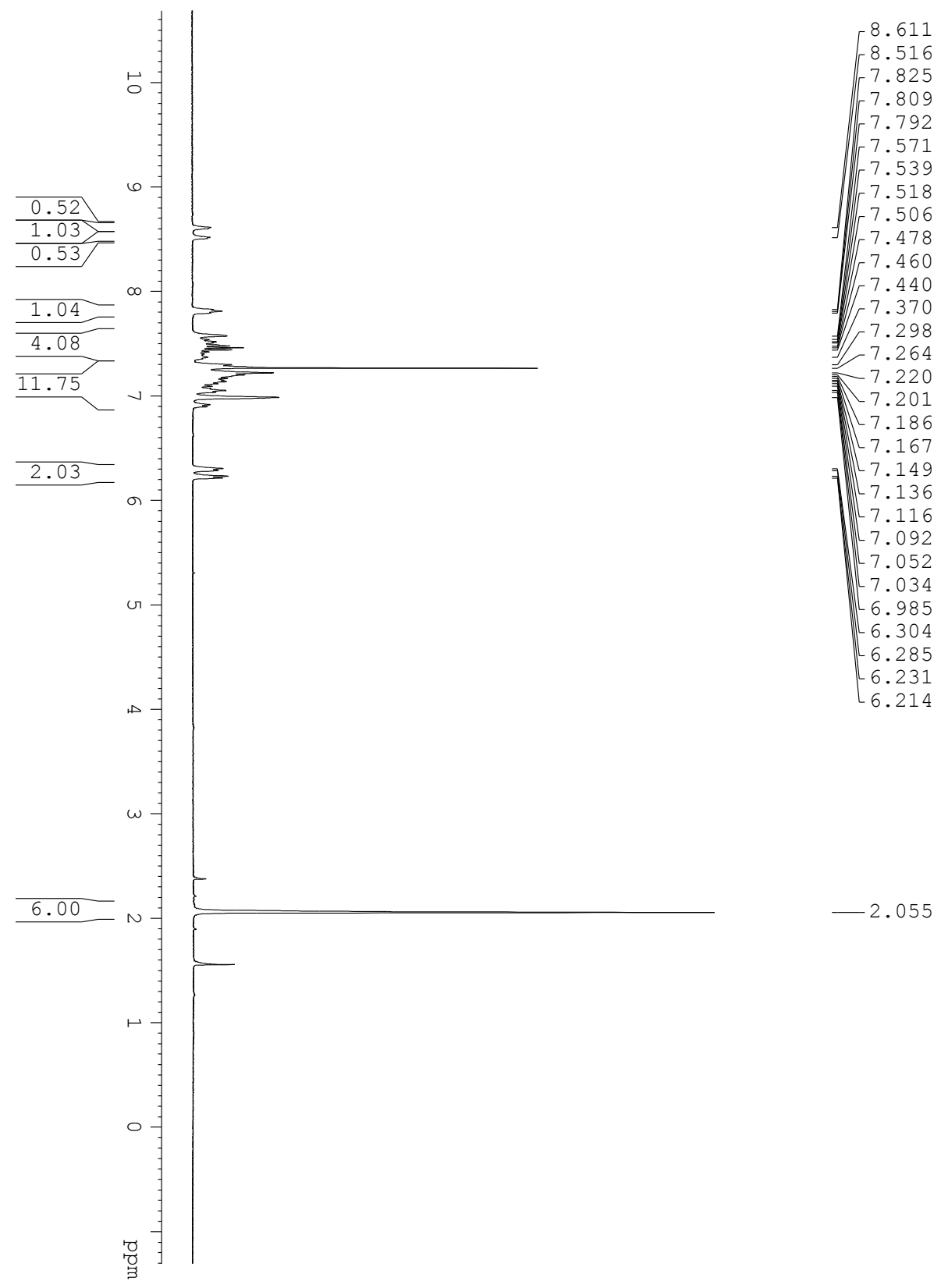

Figure S7: ${ }^{1} \mathrm{H}$ NMR of $\mathbf{L} 4\left(400 \mathrm{MHz}, \mathrm{CDCl}_{3}\right)$ 


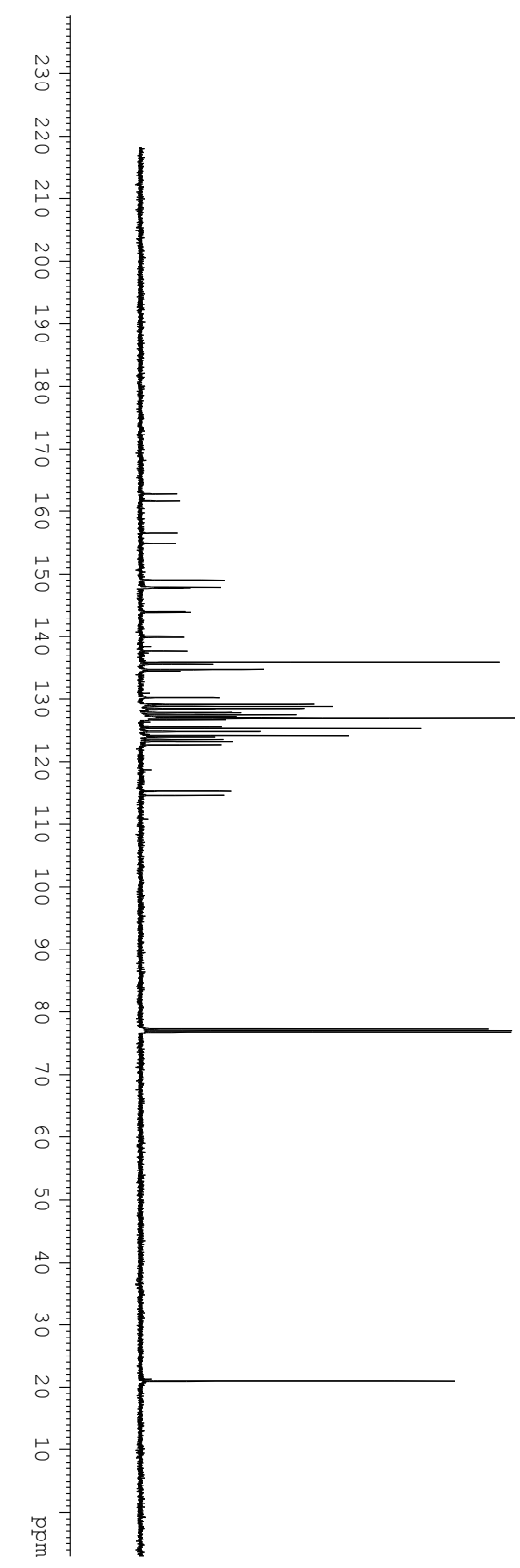

162.747

$-161.684$

156.489

$-154.877$

$-149.035$

147.823

147.718

147.643

143.994

143.851

140.037

139.821

137.719

$-135.845$

135.590

134.746

134.460

130.185

129.193

$=128.869$

128.505

$-128.292$

$-127.826$

$-127.763$

127.457

127.115

126.935

126.888

126.669

$-125.622$

$-125.399$

$-124.792$

$-124.759$

124.107

123.921

- 123.540

123.239

$-122.690$

115.269

$[114.601$

77.246

76.992

[76.737

$-20.933$

Figure S8: ${ }^{13} \mathrm{C}$ NMR of $\mathbf{L}\left(125 \mathrm{MHz}, \mathrm{CDCl}_{3}\right)$ 


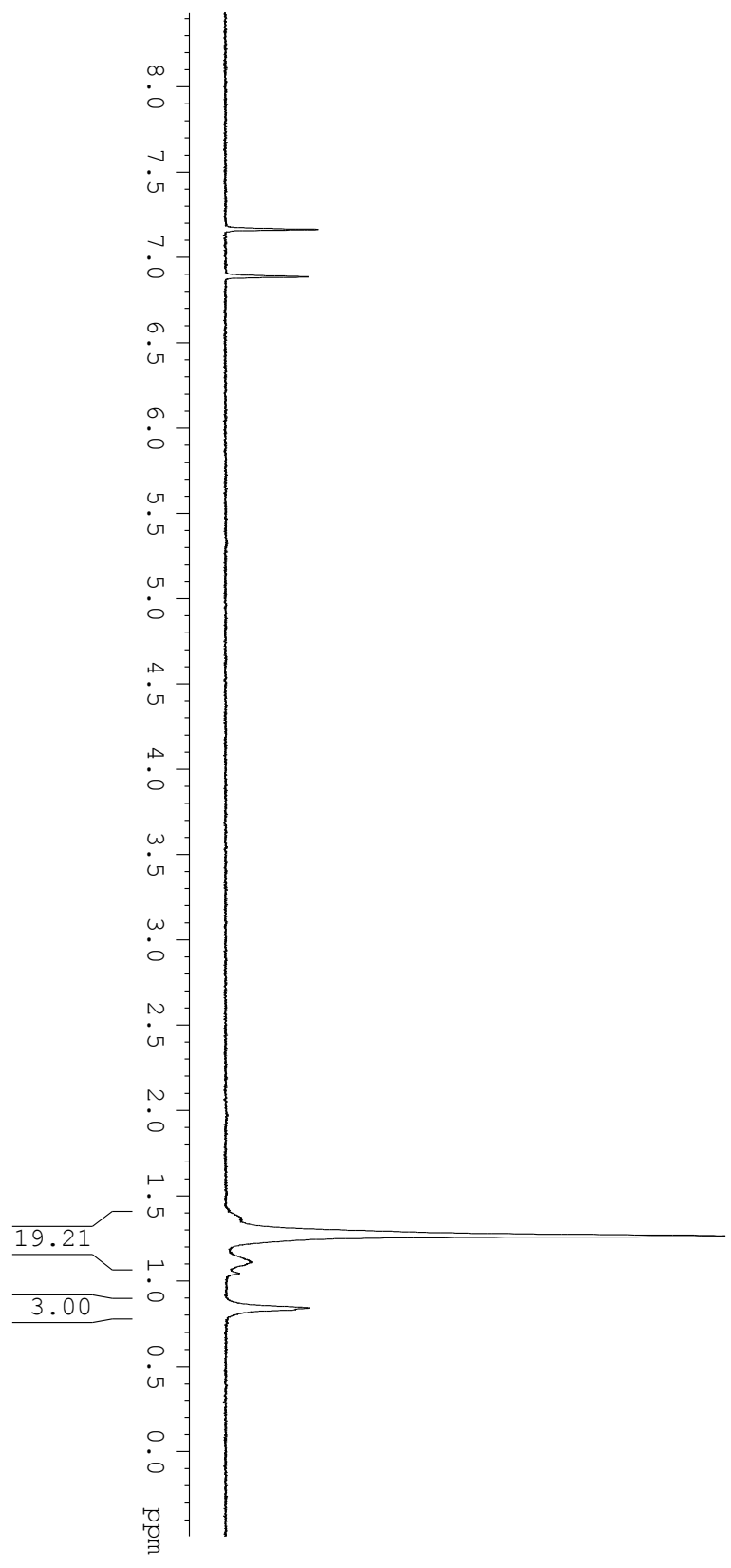

-7.163
-6.886

$-1.365$

$-1.264$

$-1.107$

$-0.842$

Figure S9: ${ }^{1} \mathrm{H}$ NMR of entry $6\left(500 \mathrm{MHz}, \mathrm{C}_{6} \mathrm{D}_{4} \mathrm{Cl}_{2}, 120{ }^{\circ} \mathrm{C}\right)$ 


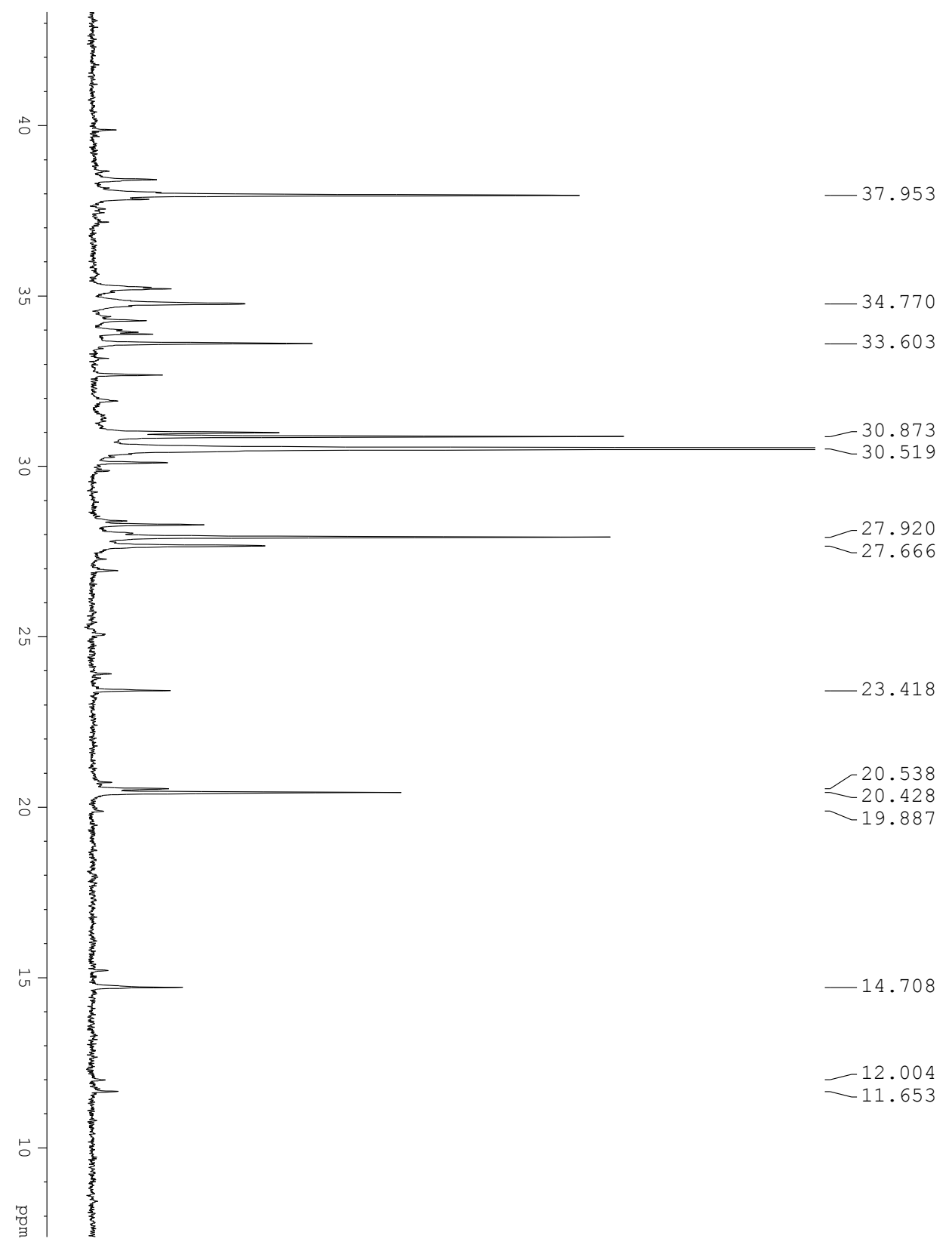

Figure S10: ${ }^{13} \mathrm{C}$ NMR of entry $6\left(125 \mathrm{MHz}, \mathrm{C}_{6} \mathrm{D}_{4} \mathrm{Cl}_{2}, 120^{\circ} \mathrm{C}\right)$ 


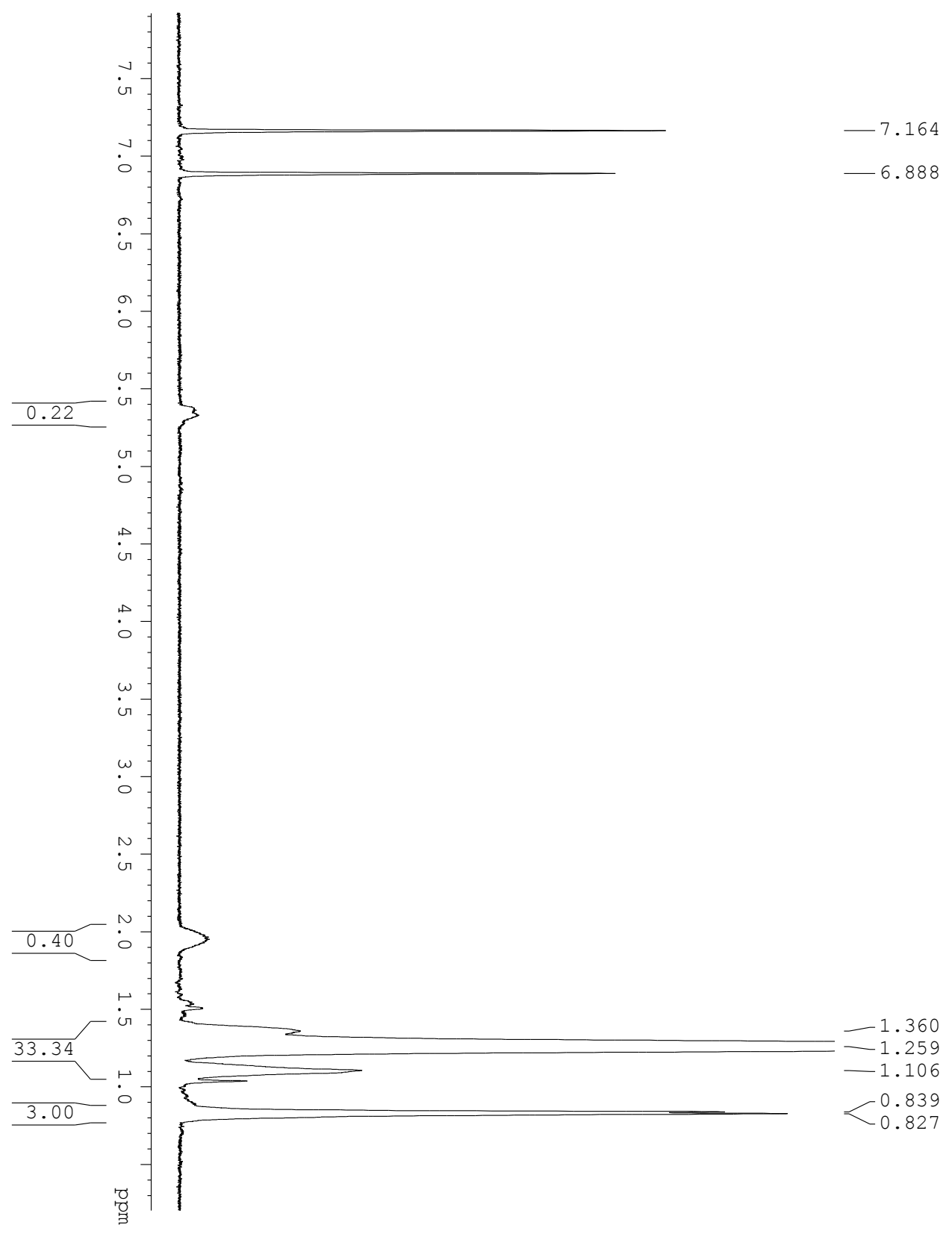

Figure S11: ${ }^{1} \mathrm{H}$ NMR of entry $10\left(500 \mathrm{MHz}, \mathrm{C}_{6} \mathrm{D}_{4} \mathrm{Cl}_{2}, 120{ }^{\circ} \mathrm{C}\right)$ 


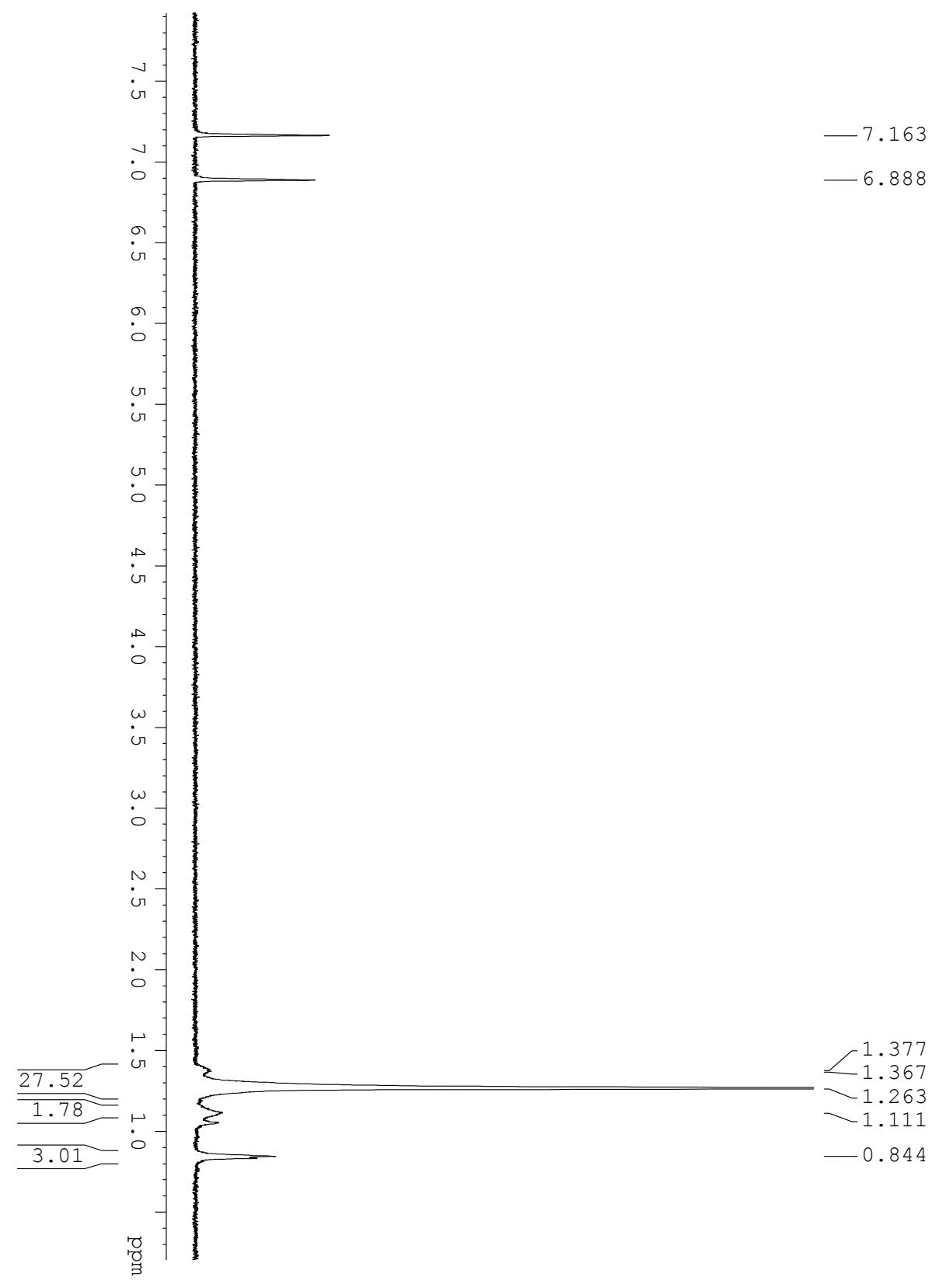

Figure S12: ${ }^{1} \mathrm{H}$ NMR of entry $13\left(500 \mathrm{MHz}, \mathrm{C}_{6} \mathrm{D}_{4} \mathrm{Cl}_{2}, 120^{\circ} \mathrm{C}\right)$ 